\title{
Beam Hardening Artifact
}

National Cancer Institute

\section{Source}

National Cancer Institute. Beam Hardening Artifact. NCI Thesaurus. Code C87016.

An artifact resulting from absorpsion of lower energy photons as the beam penetrates

through a tissue. 